\title{
Development of farmer support system on dairy and meat industry of goat utilizing ICT
}

\author{
Teppei Hirata ${ }^{1, *}$, Takeshi Miyagi ${ }^{2}$, Yasunori Nagata ${ }^{2}$, Shiro Tamaki ${ }^{1}$, Tsutomu Omatsu ${ }^{3}$, \\ Tetsuya Mizutani ${ }^{3}$
}

${ }^{1}$ Department of Information Engineering, Faculty of Engineering, University of the Ryukyus, Nishihara town, Japan

${ }^{2}$ Department of Electrical and Electronic Engineering, Faculty of Engineering, University of the Ryukyus, Nishihara town, Japan

${ }^{3}$ Research and Education Center for Prevention of Global Infectious Disease of Animals, Faculty of Agriculture, Tokyo University of Agriculture and Technology, Fuchu-shi, Tokyo, Japan

\section{Email address:}

teppei@neo.ie.u-ryukyu.ac.jp (T. Hirata),tmiyagi1130@gmail.com (T. Miyagi),ngt@eee.u-ryukyu.ac.jp (Y. Nagata), shiro@neo.ie.u-ryukyu.ac.jp (S. Tamaki), tomatsu@cc.tuat.ac.jp (T. Omatsu),tmizutan@cc.tuat.ac.jp (T. Mizutani)

\section{To cite this article:}

Teppei Hirata, Takeshi Miyagi, Yasunori Nagata, Shiro Tamaki, Tsutomu Omatsu, Tetsuya Mizutani. Development of Farmer Support System on Dairy and Meat Industry of Goat Utilizing ICT. Agriculture, Forestry and Fisheries. Vol. 3, No. 2, 2014, pp. $121-127$. doi: 10.11648/j.aff.20140302.21

\begin{abstract}
Recently, due to the rapid growth of population and food demand in the Asian region, animal feeding industry is more prosperous, so that animal food production is increasing remarkably in the region. That is, the livestock movement is getting more activated and expanding rapidly, accompanied by the enlarged globalization of economy and distribution in the Asian region. This movement of the livestock industry in the region will be expectedly accelerated by "Trans-Pacific Strategic Economic Partnership Agreement (TPP)". On the other hand, however, this rapidly accelerated activation and enlargement of livestock movement and transportation, contains an internal risk that the infectious diseases such as footand-mouth disease may break out and prevail widely in the region. In order to reduce such a risk of spreading of livestock epidemics, it is necessary to establish a global livestock information system with up-to-date technologies to achieve the food safety of developed and relieved livestock industry in the region. However, due to the budget problem for many animal farmers and the present high-priced information and communication devices, utilization movement of the modern gadget for the small-to-medium scale animal feeding management is substantially stagnant in this region. In this paper, we propose a brand new designed system with the method of ICT applications, devices and techniques to seek for the solution to this problem, concerned with the small-to-medium scale livestock feeders. Furthermore, we examine the relationships between Machine to Machine (M2M) system, database system, and Web system; those are fundamental keystones of this newly proposed system.
\end{abstract}

Keywords: Animal Industry, Infectious Diseases of Livestock, Goat, M2M, Web System, Mid-to-Small Scale Farmers

\section{Introduction}

Catastrophically widespread infectious disease of bovine spongiform encephalopathy (BSE), foot-and-mouth disease, and avian influenza gave rise to a big wave of social critical controversy for food safety of agricultural animal food products.Especially, BSE broke out in Britain in early 2000 's by which livestock were widely contaminated to the other areas outside of the country. It was pointed out that recording management of livestock information, especially about, to which organization or where it belongs, was absentminded those days. It was attributable to poor traceability information management. That sensational traceability related controversy caused a movement to construct traceability management system around the world. By such disgraceful events for animal feeding industry, cautiousness about animal food safety among consumers has been provoked, and has been widely spread. On the side of the agricultural animal farmers, it has been more natural and accelerated to disclose the important traceability results to alleviate wariness of the consumers, since then.

Therefore, it is required to establish a new information management system for animal industry to solve these problems. Our objective is to develop a new livestock information system for food production and animal 
management. This is a new information management system to recognize the feeding condition or situation by visual data for farmers, especially for mid-to-small scale animal food producers, by utilizing Information and Communication Technology. This system is designed to provide support for livestock feeders and animal food producers, besides, to analyze from diversified perspectives via big data computing, and to make advanced use on their own.

This paper illustrates one new project called "PINZA" cloud project which has been kicked off already. This is oriented to develop a new cloud system to support for agricultural animal food producers including traceability system by utilizing ICT in form of consortium mainly led by University of the Ryukyus. This project has been supported by Strategic Information and Communications R \& D Promotion Programme (SCOPE) by Ministry of Internal Affairs and Communications of Japan. The project by this consortium has now been in progress of which members are the Faculty of Engineering at University of Ryukyus, Okinawa National College of Technology, and other institutes, starting from 2011. The goal of this project is information sharing by various related parties from animal husbandry field to make scientific analysis and to disclose information.

In this project, goat is selected as model of farm animal which is one of the most common livestock in Okinawa, and is considered to be important domestic animal in other areas in Asia as well.

The project acronym, PINZA, stands for our goal, "Perfect INformation management system for Zoological Analysis (Figure.1)." PINZA also means goat in Miyakojima Island dialect of Okinawa Prefecture, where goat feeding is an important sector of agriculture, and where eating goat meat is recognized as the local custom as well.

The most important goal for this project is to build an information sharing platform for multilateral or advanced use of animal feeding information obtained through daily feeding routine of each farm animal. Many mid-to-small scale agricultural animal feeders commonly recognized in Asia, where demand for food has shown a rapid growth these years, have not obtained any proper traceability checking system. Therefore, once spread and popularized over Asia, this information access platform is expected to turn into a great potential engine for efficient feeding and faster distribution of animal food.

The basic design for this system and its applied business model were already illustrated on the previous report (Hirata et. al. [1, 2]). The importance of that business model is to take a strategy of cost reasonableness such as inexpensive device applied to data collecting of large amount from individual animal. Besides, user friendliness of access to needed information will be the strong point that any related parties including farmers, restaurants, and distributors in the line of value chain, and also, including local government officers, veterinarians, and livestock administrations, can access to such information in need under the information sharing objective.

This paper debates the structure of the research for the management efficiency of the animal feeding; purpose and developing of the database and the Web system as traceability information sharing platform on goat feeding, utilizing ICT to be oriented for our information system. This research's fruit will be, expectedly, 'prospective economic growth engine' to support the mid-to-small scale livestock farmers' management in Asia.

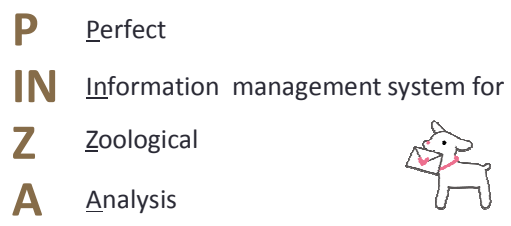

Figure 1. Pinza Cloud project.

\section{M2M Interface and the Basic Design of the System}

This chapter illustrates the functions and designs of machine to machine (M2M) interface as the keystone of the system.

\subsection{Input of Information of Animal Management through M2M (Machine to Machine) Interface}

We built the system to collect various information of the animal management in the farm through M2M (machine to machine) interface semi-automatically. M2M interface is a microcomputer for various signals transformation to transmit from the measuring devices to the database for the Internet and mobile phone terminals.

The entities of the structure of the M2M interface are illustrated as shown in Figure. 2. We made designs of the information system in which one signal from the measuring devices widely used in livestock industry (such as flow meter and load cell, or other sensors) can be transformed into another signal, for the use of the Internet of mobile phone terminals. The transformed signal was transmitted through the smartphone, then, to the database by $3 \mathrm{G}$ or $\mathrm{Wi}$ Fi network.

In the tagged microchips on the goat ears, the digitally recorded ID number of individual goat is recognized by RFID reader. In this system, RFID reader and smartphone terminal are connected by Bluetooth. Then the ID number recognized by the ear tag will be matched up to the values such as milk yield and body weight from the measuring devices. These data processing will be conducted by an exclusively designed application, installed in the smartphone terminal. The Basic design specification of processing of M2M interface is shown as following (Table. 1). The signals that can be transformed by $M 2 M$ interface is analog (voltage) or pulse signals. And these signals will 
be transformed into the adaptable signal to the smartphone with Android.

\subsection{Basic Specification of the System}

Goat is our selected pilot livestock as a model of mid-tosmall scale farm. Goat is commonly disseminated as a domestic animal in agricultural areas in Asia. Its meat, milk, leather, and hair are all to become products for commercial use. Also, its excrement is utilized for compost. That is, goat is recognized as very functional domestic animal from commercial use to compost.

Furthermore, goat is a small-sized domestic animal and its price is reasonable, so it is still vital source of income in not-rich or pinched agricultural areas still. Especially, our research focused on milk and meat production of goats as commonly seen in the Ryukyu Islands and the other Asian areas.

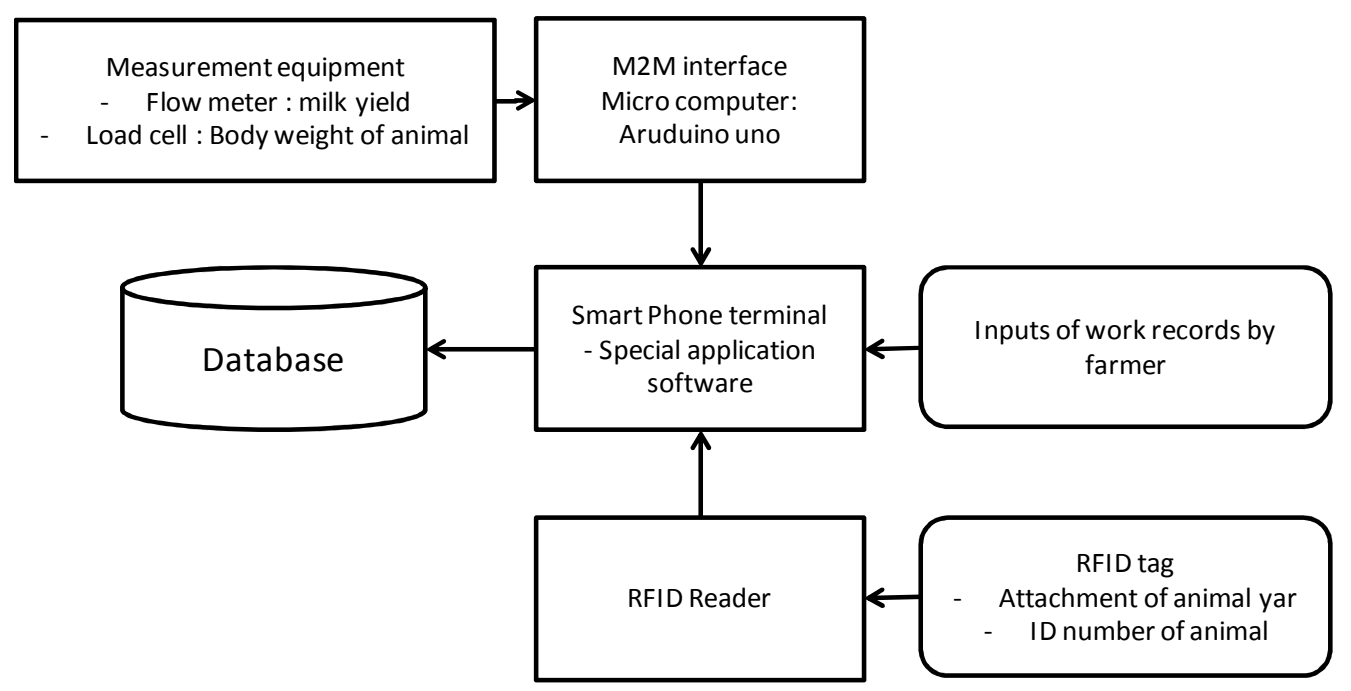

Figure 1. System construction utilizing M2M interface structure.

Table 1. The basic specifications of M2M interface.

\begin{tabular}{ll}
\hline Item & Specification \\
\hline Microcomputer & Arduino Uno \\
Embedded software & Application development language: \\
& Application Development Environment \\
Input signal & Number of channels: 8Chs \\
Output signal & Input signal : Analog and Pulse \\
\hline
\end{tabular}

\subsubsection{System of Efficient Support for Meat Goat Farmers}

There are some important points for goat feeder to realize efficient management. Goat feeder should increase fine goats by selective breeding, with lower cost, and to make them grow faster. Also it is necessary to predict the change of the goat body weight properly, in order to forward at the best timing. Another important point for the improvement of goat farming management is, proper management of reproduction; efficient increase of the female goat. For meat goat feeding management, three basic functions were activated such as measuring and predicting of body weight, and reproduction management. The detail of the system was illustrated by previous work (Oshiro et. al. [3]).

\subsubsection{System of Efficient Support for Dairy Goat Farmer}

For dairy goat farming, it is required to properly manage the calving and reproduction to periodically keep the track of milk yield. Flow meter is used as measuring method of milk, put in the pipeline from the teat cup to the bucket. The unsteady flow current of milk in the pipeline is caused by the negative pressure of the milk tank. To overcome this problem, the centrifugal machine should be placed before the flow meter to remove the air from milk current. However, such apparatus leads to budget problem. It would not be possible to obtain high-priced apparatus for the midto-small scale individual farmer. To seek for the solution to this budget problem, we placed a load cell under the milk tank that could measure the weight of milk to make an approximate milk yield estimate of each goat instead of using flow meter. This low cost device is a great progress we made in measuring method of the milk yield, even though it may be a little inferior in terms of precision.

The user scans the microchip in the goat ear at the time of starting and finishing of milking since this scanning works as trigger of on and off of measuring in this system. Time spent of the milking and ID numbers of the milking workers are also recorded. The measured data were matched up to the ID of the goat by the application installed in the smartphone. Length of milking time is an important indicator for dairy goat management concerned with labor cost. Milking is one of the most time consuming task of daily routines, which is conducted in the early morning and the evening. Therefore, the labor cost is occupied to a considerable degree compared to the desirable working hours of the goat farming management. Therefore, proper selection of the goats, depending on the milking time, leads to the efficient management. Such related important information is also contained in the database of this system. 
Furthermore, the function of the milk yield prediction was added to the system to support the efficient management. The graph of lactation in milk yield shows growths to a higher peak of the milk yield but reduce persistency as a gamma curve (4). The examples of lactation curve is shown as Figure. 8.

As the function of milk yield prediction, the Wood model was used as algebraic model [4].

By this function of the milk yield prediction, the dairy goat farmers can obtain the essential estimate or indicators of the milk yield changes, or the characteristics of the dairy goat for the selective breeding later on. The basic functions of the system are shown at Table 3. The details about this system were reported by Ijichi et. al. [5].

\subsubsection{Structure and Workflow of the System}

We, here, discuss the structure and workflow of the whole system. The system was built in the server of the Faculty of Engineering, University of the Ryukyus. The server contains the database system, the program for analysis on animal farming industry, and Web system for the users who can view various data.

Data from measuring devices are input via M2M interface to the database automatically. The details of the database will be discussed in the next Chapter. The system contains the database and data analysis program so that the needed information is picked out for analysis. Workflow of the whole system is illustrated at Figure. 4.

Table 2. Basic functions of the control system for meat goat breeding.

\begin{tabular}{|c|c|}
\hline Function & Specification \\
\hline $\begin{array}{l}\text { Measurement } \\
\text { of body weight }\end{array}$ & $\begin{array}{l}\text { - Measuring the weight of the individual } \\
\text { livestock. } \\
\text { - During the measurement of body } \\
\text { weight, individual number and measurement } \\
\text { data are recorded to the database. }\end{array}$ \\
\hline $\begin{array}{l}\text { Body weight } \\
\text { prediction }\end{array}$ & $\begin{array}{l}\text { - Make predictions of future changes in } \\
\text { the individual's body weight. }\end{array}$ \\
\hline $\begin{array}{c}\text { Breeding } \\
\text { management }\end{array}$ & $\begin{array}{l}\text { - Recording mating ( Records of } \\
\text { parents). } \\
\text { - Alarm function of the expected date of } \\
\text { birth. }\end{array}$ \\
\hline
\end{tabular}

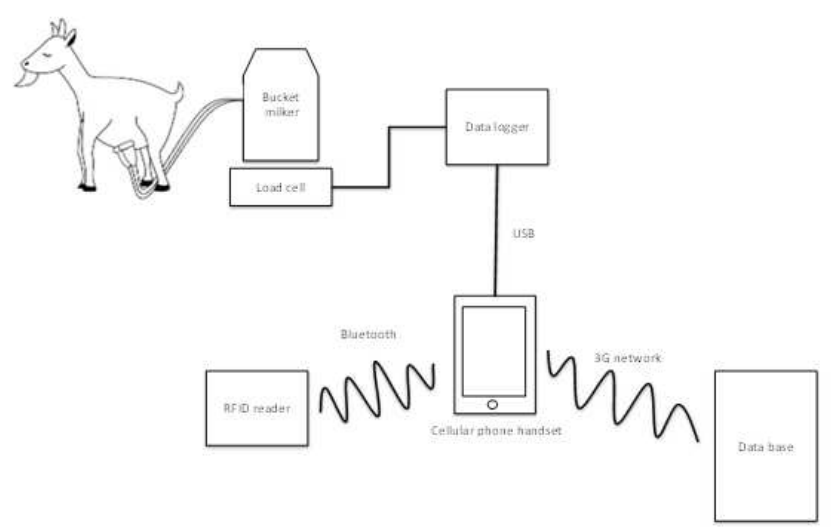

Figure 3. System configuration diagram of milk yield measuring.
Table 3. Basic functions of the daily goat management.

\begin{tabular}{|c|c|}
\hline Function & Specification \\
\hline $\begin{array}{l}\text { Milk yield } \\
\text { measurement }\end{array}$ & $\begin{array}{l}\text { - Recording the milk yield and time } \\
\text { required for } \\
\text { the milking } \\
\text { - Measured by a load cell placed at the } \\
\text { bottom } \\
\text { of the bucket milker }\end{array}$ \\
\hline $\begin{array}{l}\text { Milk yield } \\
\text { prediction }\end{array}$ & $\begin{array}{l}\text { Make predictions of future changes in the } \\
\text { individual's milk yield }\end{array}$ \\
\hline $\begin{array}{l}\text { Breeding } \\
\text { management }\end{array}$ & $\begin{array}{ll}\text { - } & \text { Record of mating } \\
\text { - } & \text { Calculate the number of days after } \\
\text { delivery } & \end{array}$ \\
\hline
\end{tabular}

\section{System Work Flow}

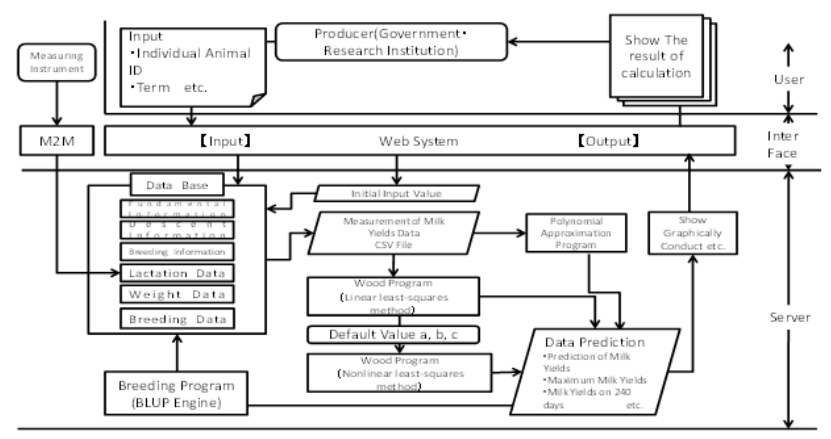

Figure 4. Overall configuration of the system.

\section{Building of the Database}

This system is aimed at information sharing of various livestock by related parties such as farmers, veterinarians and administrative organizations. The system covers various livestock information of basic health, mating, milking, and any other related data. And these data are centrally controlled for management. The database for this system was designed as a relational database. The main entities of designed table are as follows.

- Basic livestock information: identification number of the animal, birth date, sex, ID number of the parents, nickname, the name of owner, etc.

- Organization information: name of the organization, address and geographical information of organization, name of representative, access authorization.

- User's information: name of the user, birth date, name of affiliation, qualifications (veterinarian, artificial inseminator)

- Body weight information: measuring date, measuring value, ID number of device

- Milking information: milking date, name of milking person, quantity of milk yield, length of milking time

As an example of building the relational database, ER (Entity Relationship) diagram of farm animal management is illustrated at Figure. 5. MySQL was chosen as the Database Management System (DBMS) for development. 


\section{Development and Implementation of Web System}

\subsection{Basic Design of Web System}

Web system was chosen for user interface to operate various information managements, instead of exclusive application software. Types of the users' OS or terminals are miscellaneous, depending on each person or company. Because Web system is effective under such changeable environment, it is more attractive than exclusive use applications.

By this Web system, the user logged in from top page once, the main page will appear. The main page shows lists of goats kept in the same organizations. On this main page, each goat's name shows up by order of numbers of references reproductive management such as mating, delivery, and lactation from top to bottom. Since the delivery date is one of the most important items for livestock management, this page was also designed that the listed order can be adjustable to delivery date order. Furthermore, the goat ID number is clicked, each animal's information will appear in detail (the date of birth, pedigree information for three generations, reproductive information, body weight information, etc.) on the screen.

On the main page, also, tabs for click of reproduction, lactation, body weight management are prepared. On each individual goat page, the same tabs of the main page are placed as users can view. Example of the main page is shown at Figure. 6, and the system chart of structural page views is illustrated at Figure7.

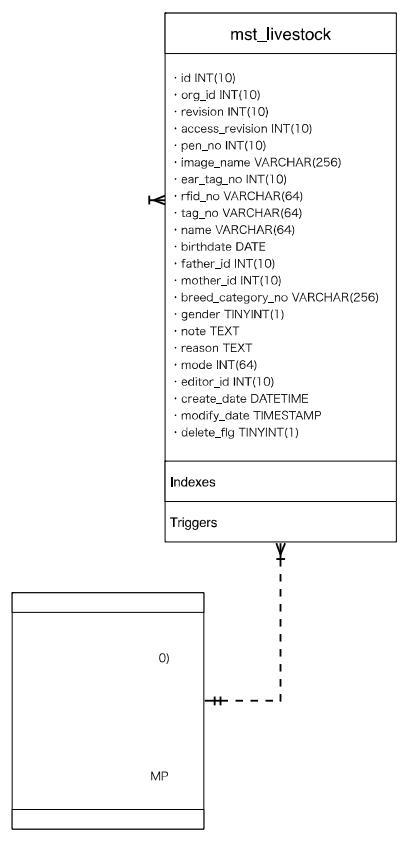

Figure 5. Entity relationship diagram of database on body weight management system.

\subsection{Details of Each Function and Page Design of the System}

\subsubsection{Page Design and Function of Reproduction Management}

Subpages of management for mating and delivery were also established. On the page of mating, there show up the goat IDs list by the order of probabilities dates of mating, which are confirmed in estrus, and are likely to copulate within sooner days. The goat ID button should be clicked, when the user wants to input mating data.

Also, natural mating or artificial insemination can be chosen then. The record of mating was once saved, and alarm was set, then a reminder would be showing up after 150 days of average pregnancy period of goat. The delivery management page shows the list by order of the expected delivery dates. Clicked the goat ID button, the user could keep the record of delivery information such as the ID number of the kid, each sex of kids, and the number of the neck tug placed for tentative use.

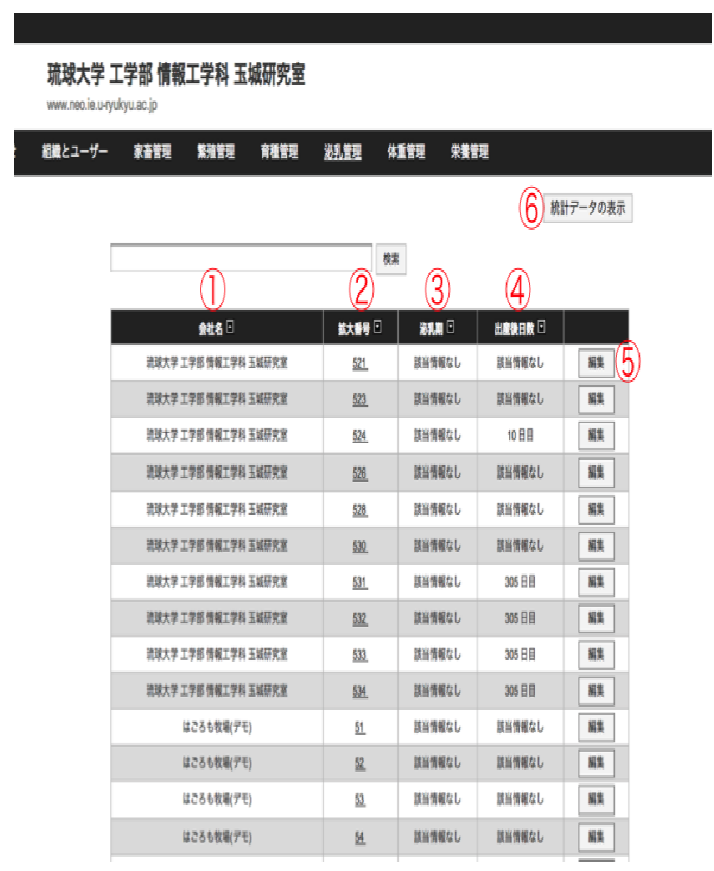

Figure 6. Example of user interface of this system.

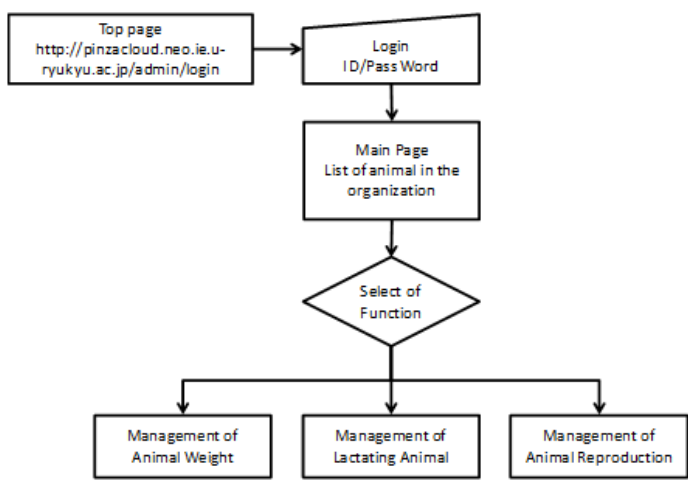

Figure 7. Schematic diagram showing the transition page of Web System. 


\subsubsection{Page Design and Function of Lactation Management}

In this page, the goat IDs are arranged in the list by order of the lapse days after its delivery. Male goat data are not showing up here; only female ones appear. Clicking of female goat ID number will move to the page of detailed lactation information. On the detailed lactation information page, the prediction of milk yield would be demonstrated as graph. Also, the lapse days, details of the goat's historical data of lactation would appear. An example of the detailed page is shown at Figure.8.

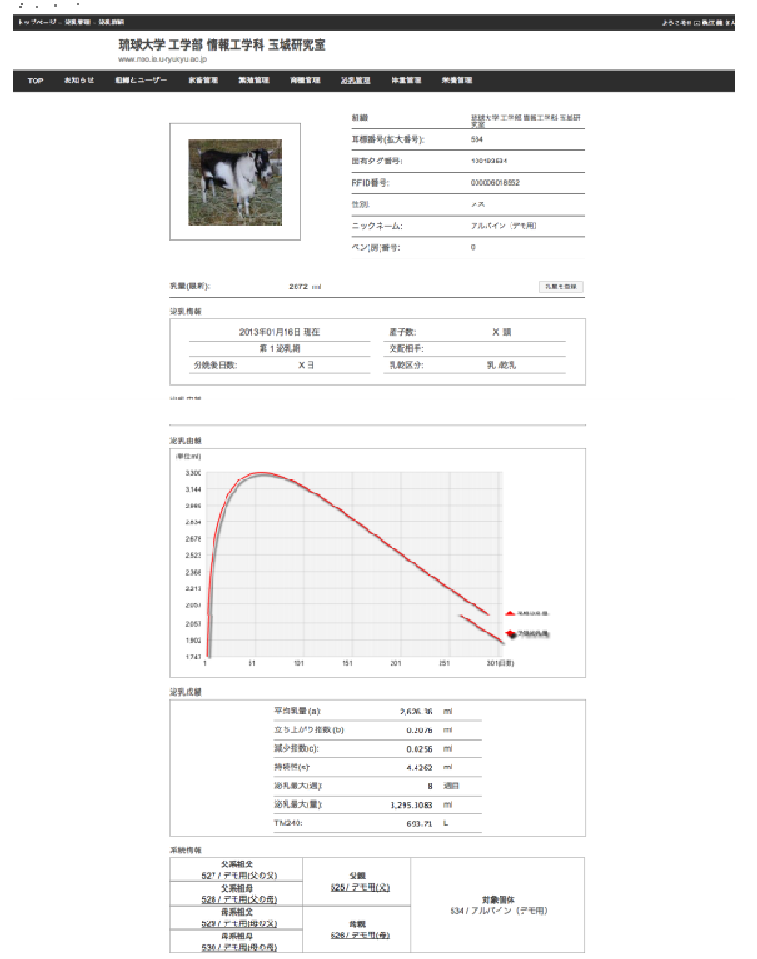

Figure 8. Design of lactation management screen.

\subsubsection{Environment of System Development}

This section explains the environment of system development for Web system. The details are described at Table 4.

Table 4. Development environment of the web system.

\begin{tabular}{ll}
\hline Server & Development environment \\
Database server & OS : CentOS 6.3 \\
& DBMS $\%$ MySQL 5 \\
& OS : CentOS 6.3 \\
Web application server & Development language: \\
Web API server & PHP 5.2.6, Python 2.6, C/C ++ \\
& Web service : apache 2.2 \\
\hline
\end{tabular}

※DBMS : database management system

\subsection{Development of the Database}

Our database was built as relational database by utilizing of free soft MySql as a database management system (DBMS). Usage of free software leads to easy modification of the system to answer to various requests by users.
The business model which we aimed at is that, not limited to, goat feeders but any other various related parties such as veterinarians and governmental officers can make use of the database[1]. Provided that all of the goats in Japan were enrolled in this system, then, miscellaneous kinds of researches and analysis could be possible from various points of perspectives or concepts. It is due to livestock goat regulations under different local circumstances. For example, goats are kept as livestock for dairy use in Hokkaido, and milk are used as raw material for cheese. In this case, if the goat farming is needed to be put under the local government management, then the regulations of milk or lactations are concerned to obey. On the other hand, in Okinawa, meat goat feeding is more popular. Then, the goat's birth dates are very important. The strict management of the birthdates is imposed to the meat goat feeders. It is because Okinawa prefectural regulation requires every each goat of 12 month years old, or older, to take inspections of prions of BSE; that is, goats under 12 month old are free from cerebral inspections.

As such above mentioned, the way of using the database will differ from one to another prefecture or area. So, it would be difficult to meet with the each different need by building each different database. We chose to arrange the open source for the database management to satisfy different needs. Adopting other new technologies, like Open ID as solution for rearrangement of access authorization, would be the key to further progress in system building and advanced use.

\subsection{Development of Web System}

We adopted Web system by cloud system to provide the users with data service for comfortable and friendly use, which any related users can operate under any numerous communication environments. For cloud system operation, as a matter of course, environment of the Internet connection is needed around the users. However, from the average mid-to-small scale farmers' view of the world, seemingly, there are very limited numbers of farmers who have been provided such environment. As we can see, the mobile phone disseminated rapidly nowadays. The Internet environment are widely spreading with accelerated speed than used to be, even in the agricultural areas also, by worldwide distribution of the smartphone which has an important role. Under this research, we constitute and offer a brand new proposal, faced by such a rapid dissemination of up-to-date communication style at present and even more advanced style coming in the future. However, yet for now, the simulated tests of the actual operation for Web system were conducted only in the browser installed in the PC. Therefore, the system should be improved, to be applicable to more miscellaneous kinds of the Internet environment including smartphones. Also, operational abilities of the smartphone seem to be limited with the built-in browser for now, so that a new exclusive-use application for the system should be taken steps for development for further progressed utilization. 


\section{Future Development}

This final chapter debates our foreseeable future development from this project's results. Efficient management of livestock farmers' daily work was our focus for this project. Progress in communication of farm animal information will bear great fruits, we assured, not limited to daily animal management efficiency, but prevention of infectious disease, further progress in public health, and other various advantageous merits. For example, It is known that the measurement of milk yield plays an important roles in management of mastitis and milk fever; disease specific to dairy animals. Also, It would be considered that the management of body weight also becomes easier the discovery of diseases, including zoonotic diseases. For this reason, we need to proceed in this research further, as veterinarians can easily connect to the information system, or the other important related parties can do so for further improvement of daily management by our future study.

This database also may be useful for animal quarantine procedure. Hirata et al. [6] subjected that mathematical model of infectious disease and its application (simulation of transmission of pathogens) is useful for animal husbandry industry. However, many of case, basically data are lucking to conduct simulation. Our database would be complement the luck of data.

\section{Conclusions}

In this study, the design of information management system to support the dairy and meat goat farmers have been performed. The functions of this system are weight management of animals and milk yield management. In addition, the system also has the ability to integrate information of these.

In this study, the design of system was performed, but the verification test was not performed. It is required that the verification of stability of the system, and statistical research of processing. To be complete this study, it is necessary that these problems can be solved.

\section{Acknowledgement}

This study was conducted with the assistance of the Ministry of Internal Affairs and Communications of Japan by SCOPE scheme. We were able to achieve full cooperation of Hagoromo Bokujo, Co. Ltd. RFID tag and readers were provided by Surge MIYAWAKI Co. Ltd. And this study was supported by Okinawa Cross Head Co., Ltd. and NTTDATA CUSTOMER SERVICE Corporation. We would like to presence the appreciation.

\section{References}

[1] T. Hirata, K. Kuwae, A. Shimabukuro and S. Tamaki, "Development of quality control and breading management system of goats based on information and communication technology", ASTL Vol. 16 ASAP, ISSN: 2287-1233, pp85-89, 2012

[2] T. Hirata, K. Kuwae, A. Shimabukuro and S. Tamaki, "Development of quality control and breading management system of goats based on information and communication technology", Studies in Informatics and Control, pp. 81-90, 2013.

[3] M. Oshiro, Y. Shiroma, A. Ijichi, T. Hirata, C. Gakiya, K. Kuwae, M. Shinjo and S. Tamaki, "Development of information management system for livestock production by using Information and Communication Technology" Record of 2012 Conference of IEEE in Okinawa, pp8082,2012

[4] Wood PDP: "Algebraic of the lactation curve in cattle", Nature 216, 164-165,1967

[5] A. Ijichi, Y. Shiroma, M. Oshiro, T. Hirata, C. Gakiya, K. Kuwae S. Tamaki and M. Shinjo, "Development of automatic measurement systems of goat milk yield and milk yield prediction system using RFID tags and mobile phone terminal", Record of 2012 Conference of IEEE in Okinawa, pp83-86,2012

[6] Teppei Hirata, Yoshihito Yonahara, Faramarz Asharif, Tsutomu Omatsu, Takeshi Miyagi, Yasunori Nagata, Tetsuya Mizutani, and Shiro Tamaki, "A Study on Mathematical Model of Caprine Arthritis Encephalitis (CAE) and Development of Animal Quarantine Information System Adapted for Small Island" IEEK Transactions on Smart Processing and Computing, vol. 2, no. 4, August 2013 